\title{
PRESENCIAS INSÓLITAS DE LA MUERTE EN EL IMAGINARIO COLECTIVO PERUANO: ALMAS EN PENA, FANTASMAS O ÁNIMAS
}

Gloria Cristina Flórez Dávila Universidad Nacional Mayor de San Marcos

\begin{abstract}
RESUMEN
Nuestro trabajo se interesa en presentar las presencias insólitas de la muerte que se han manifestado desde el período virreinal hasta la actualidad en nuestro país. Las numerosas y variadas fuentes consultadas ayudan a conocer cómo esas almas en pena, fantasmas o ánimas han sido percibidas, sentidas y posteriormente transmitidas a la colectividad. Asimismo, esas tradiciones del mundo de ultratumba permiten acceder al imaginario colectivo de nuestras sociedades en la larga duración y las condiciones que han favorecido la integración de elementos procedentes de diferentes culturas.
\end{abstract}

\section{PALABRAS CLAVE}

Almas en pena / Fantasmas / Muerte / Imaginario colectivo / Perú.

\begin{abstract}
Our work shows unusual presences of death that have been demonstrated since the viceroyalty period up to nowadays in our country. Several and varied sources consulted help us to know how these souls in Purgatory, ghosts, spirit have been perceived, felt and then transmitted to the community. Therefore, these traditions of life beyond the grave allow us to understand the collective imaginary of our societies in a long-term and the conditions that favored integration of elements coming from different cultures.
\end{abstract}

\section{KEY WORDS}

Souls in Purgatory / Ghosts / Death / Collective Imaginary / Peru. 
Este trabajo se interesa en presentar los aspectos más destacados de las investigaciones realizadas en años anteriores, complementadas además con el dictado del seminario Historia de las mentalidades ${ }^{1}$. Nuestro objetivo no era probar la existencia de esas presencias insólitas de la muerte que reciben numerosas denominaciones (almas en pena, fantasmas o ánimas, las más utilizadas), sino conocer cómo se percibían, sentían o imaginaban. Asimismo, deseábamos precisar los diferentes canales de transmisión utilizados, orales principalmente, si bien en ciertos casos, los escritos y las imágenes han tenido importancia.

En cuanto a la aparición fantasmal tiene una definición muy amplia y en su mayoría referida a los espíritus de gente común, quienes por diferentes razones no han alcanzado el descanso eterno. Si bien han atravesado la frontera que separa el mundo de los vivos de aquel de los muertos pueden presentarse, en diferentes formas, lugares, ocasiones en la comunidad de la que formaron parte en algún momento.

Hablar de los fantasmas nos obliga a tener en cuenta una situación fundamental: la muerte, un evento concebido tradicionalmente como una entrada al Más Allá o mundo de ultratumba. Es una experiencia única porque se relaciona con un estado definitivo y que afecta con seguridad a todos los seres vivientes. No obstante, era una situación difícilmente aceptada en las sociedades tradicionales y que ha favorecido en los seres humanos la creencia de una nueva vida de los difuntos, al menos durante cierto tiempo (Delumeau, 1978, p. 111).

El estudio de esas presencias insólitas de la muerte es sumamente importante para los historiadores, atraídos por el estudio de las mentalidades de una sociedad. Esas imágenes del Más Allá muestran su persistencia a través del tiempo pero las diversas condiciones que se presentan en el devenir histórico afectan los relatos fantasmagóricos. Ellos han sobrevivido pero han sufrido transformaciones y se han adecuado a los cambios culturales y tecnológicos, así como a las necesidades individuales y grupales. $\mathrm{Si}$ bien esos relatos pueden generalmente ser considerado como anecdóticos, ilusorios o faltos de racionalidad, no podemos negar su importancia en nuestras tradiciones y los variados componentes que han participado en su elaboración o mejor aún, reelaboración en el transcurso del tiempo.

1 Todos ellos realizados en la Facultad de Ciencias Sociales de la Universidad Nacional Mayor de San Marcos. 
Debemos tener en cuenta la afirmación de un especialista, la muerte es una enorme invariante (Vovelle, 2005, p. 13) y no ha dejado de evolucionar, tanto en sus causantes, rituales del entierro pero muy especialmente, en lo concerniente a los comportamientos, actitudes o gestos de acompañamiento a través del tiempo. Así, es posible acceder a un corpus básico de las reflexiones sobre la muerte compuesto por testimonios muy variados y numerosos, si bien no todo lo completo que desearíamos tener.

La forma particular de existencia que se va a prestar a los difuntos dependía del desenvolvimiento de los "ritos de pasaje" de la muerte: los muertos regresan preferentemente cuando éstos no se han podido efectuar normalmente en el duelo o funeral. Esos muertos son generalmente considerados maléficos, manifestándose una dimensión antropológica y universal de su regreso, puesto que las creencias e imaginario dependen ante todo de las estructuras y el funcionamiento de la sociedad y de la cultura en una época dada. Esta situación va a relacionarse estrechamente con las creencias religiosas en las grandes civilizaciones de la Antigüedad, como en Grecia y Roma.

El cristianismo ha realizado importantes cambios en la concepción de la muerte y de los "aparecidos" y en el período comprendido entre los siglos IV al $\mathrm{X}^{2}$, los padres de la iglesia - como San Agustín- manifestaron el rechazo a esas apariciones, pero su fueron integrando las creencias paganas a las cristianas. La Iglesia utilizó mecanismos sumamente interesantes en su catequesis y buscando combatir esas creencias, contribuyó a su difusión al incorporándolas a una perspectiva de salvación eterna. Una ayuda importante ha sido la celebración de las fiestas de los muertos en el monasterio de Cluny a partir del siglo $\mathrm{X}$, que insistían en la relación entre vivos y muertos, puesto que los difuntos necesitaban la ayuda de los vivos para descansar en paz y era una obligación de sus deudos ayudarlos dentro de una visión binaria del mundo de ultratumba (Lecouteux, 1999, p. 237).

De esta manera, se presentaba una variación en todo lo concerniente a la denominada "memoria de los muertos" y en los siglos siguientes, los difuntos salieron cada vez más de la sombra para convertirse en las almas en pena, quienes necesitaban el apoyo de ritos religiosos de quienes habían sobrevivido, no solamente para lograr el descanso eterno sino también la bienaventuranza. Esa solidaridad entre ambos grupos era muy necesaria para

2 Son importantes las obras de San Agustín, Tertuliano, Isidoro de Sevilla entre otros. 
quienes habían tenido una muerte imperfecta y mediante ritos como: misas, rezos y limosnas se podría asegurarle un tránsito seguro. Posteriormente, las creencias existentes se complementaron con el "nacimiento del tercer lugar”, el purgatorio, magistralmente estudiado por Jacques Le Goff, así como por una literatura muy variada como cuentos, poesías, exempla y hagiografía, al igual que imágenes (Anexo I) que permiten ampliar nuestro conocimiento de esos personajes de ultratumba.

Esos siglos XI al XIII son muy importantes para el conocimiento de nuestro tema, la cartografía del Más Allá se ha vuelto más compleja con nuevos espacios: el mencionado purgatorio y el limbo para los no bautizados. Asimismo, encontramos representaciones de los difuntos, a los plácidos yacentes, se agregan representaciones divertidas (la muerte jugando al ajedrez) o moralizadoras (dicho de los tres vivos y tres muertos, incluso las relacionadas con la Santa Compaña gallega o procesión de las ánimas (Anexo II), emparentadas con tradiciones célticas o germanas como las cabalgatas nocturnas o el paso de la mesnada Hellequin.

Los relatos de fantasmas buscaban ejemplarizar, de ninguna manera se interesaban en asustar o causar miedo, inclusive los sofisticados relatos cortesanos tenían como objetivo fundamental divertir a su audiencia (Joynes, 2001, pp. XI, 45). A partir del siglo XIII, esos aparecidos fueron aumentando en número pero sus funciones de protección y consejo a sus deudos fueron cambiando, adquirieron características amenazadoras o atemorizantes, que se relacionaban con la forma de vida que había tenido el difunto.

Los cambios ocasionados por la crisis de la Edad Media Tardía dieron lugar desde fines del siglo XIII a representaciones iconográficas muy interesantes como las conocidas danzas de la muerte o la muerte cadavérica. Se interesaban en resaltar el sentido macabro y la inexorabilidad del destino humano. A partir de del siglo XVI, la pastoral post tridentina fijó definitivamente los cuatro lugares de ultratumba y sus características se han perfeccionado en los siglos siguientes y se han reflejado en los diferentes ámbitos de la cultura virreinal ${ }^{3}$.

En el caso de nuestro país, el proceso de aculturación realizado por los conquistadores españoles, especialmente en lo religioso no fue fácil, como se comprueba en los diferentes trabajos de especialistas peruanos y

3 Este tema lo estamos desarrollando en nuestra investigación en curso: Geografía de los espacios de ultratumba. 
extranjeros. Si bien se utilizaron diversos mecanismos como la prédica o el folklore, una serie de dificultades no permitieron que la catequesis fuera exitosa, a diferencia de las que se habían realizado en diferentes momentos de la Edad Media y que habían dado lugar a lo que se ha denominado "cristianismo folclórico". En nuestro territorio debemos reconocer la importancia del legado prehispánico cuyas concepciones sobre cosmos y caos permiten comprender las normas sociales y su relación con el comportamiento de las almas. Por lo tanto, la conducta después de la muerte está relacionada con la actuación que tuvo el difunto en vida, tal como era el caso en las sociedades medievales.

Los decretos de los Concilios Tridentino y Limenses buscando un cristianismo acorde con una pastoral más estricta y su relación con la labor de los extirpadores de idolatrías nos permiten comprender la importancia de los mecanismos utilizados para moldear las mentalidades de los fieles, como los sermones y la confesión, así como las representaciones iconográficas del mundo de ultratumba. Sin embargo, era difícil desarraigar completamente las ideas procedentes del medioevo occidental cristiano e incluso del mundo pre-cristiano en los mismos evangelizadores. Es interesante señalar la perennidad de ciertos relatos existentes en el mundo virreinal como los que tratan de las procesiones de ánimas, el cochero del diablo o el monje sin cabeza y que serían conocidas en los siglos siguientes gracias a las Tradiciones de Ricardo Palma.

¿Qué decir además de la rica iconografía del triunfante arte barroco como los murales pinturas del juicio final o del infierno en nuestras iglesias o la conocida escultura de la Muerte de Baltazar Gavilán y que nos trae a la memoria la imagen de Ankou, el mensajero celta de la muerte? (Anexo III), incluso los dibujos que se encuentran en un protocolo notarial limeño del siglo XVII y que podría ser una representación fantasmagórica.

Ese período del barroco triunfante del siglo XVII ha coincidido también con situaciones especiales en Europa como la cacería de brujas y la persecución de prácticas pre cristianas, esta última muy similar a nuestro proceso de extirpación de idolatría que se fueron superando lentamente, abriéndose lentamente el camino para una visión diferente de la muerte en el siglo XVIII, marcada por los cambios estudiados detalladamente por Vovelle en sus obras. Es el caso de la ubicación de los cementerios en las periferias urbanas, los ritos mortuorios, la disminución en el número de las misas de sufragio y en cierto modo, este nuevo culto a los muertos, marcado 
por los postulados de la Ilustración y la ideología burguesa, afectaría la legitimidad de las creencias en fantasmas y las fueron relegando al mundo de las supersticiones populares.

Las proyecciones de las revoluciones burguesas en el siglo XIX, tanto en lo económico como en lo político se relacionaron con otros componentes culturales e ideológicos (liberalismo, positivismo y socialismo), que moldearon nuevos comportamientos y visiones del mundo y que afectaron aún más a la existencia de esos omnipresentes fantasmas de los siglos anteriores, presentándolos como expresiones de lo irracional o muestras clara de la superstición popular. Sin embargo, gracias a la influencia del Romanticismo, ligado a elementos como el folklore y una visión idealizada de lo medieval, así como el papel de las emociones y sentimientos, dieron lugar al éxito de la llamada novela gótica, despertando nuevamente el interés por lo fantástico y lo fantasmagórico.

Gracias a temas como los amores infelices truncados por la muerte en sus diferentes variantes, como el ejemplo que insertamos (Anexo IV), el descubrimiento de tesoros (como son narrados por Irving o Bécquer), los vampiros en la clásica novela de Bram Stoker o, mejor aún, las narraciones de Sheridan Le Fanu o John Polidori mostraron el aspecto extremadamente peligroso y aterrador de esas presencias de la muerte. Los notables avances en el siglo XX del mundo industrializado y su tecnología podían ofrecer a las sociedades la sensación de un mayor dominio del universo en el que vivían y permitir la desaparición de esas creencias milenarias en los aparecidos. Sin embargo, esa preocupación por el mundo de ultratumba y sus inexplicables manifestaciones no desapareció sino que se siguió manifestándose como es el caso del espiritismo y sus prácticas muy difundidas con éxito y también el impulso que ha tenido y sigue teniendo cada vez más en el mundo industrializado una amplia producción literaria ${ }^{4}$, así como de filmes, series televisivas o juegos informáticos que utilizan medios muy sofisticados, acordes con los gustos de un público ávido de sensaciones de terror y espanto. Queda la tarea de explicar las razones de esta situación en los diferentes grupos y una realización interdisciplinaria permitiría una mejor comprensión de la complejidad de nuestra sociedad.

4 Prueba de ello la tenemos en el éxito de librería de las publicaciones de Anne Rice, Entrevista al vampiro y las numerosas Antologías de Cuentos fantásticos o de terror en los últimos años. 
Nuestro trabajo (Flórez, 2014, pp. 167-183) nos ha permitido elaborar una taxonomía de esas presencias insólitas de la muerte, la que sintetizamos a continuación:

1) La terminología utilizada: Alma o almas en pena, Almita, Ánima o ánimas, Aparecidos, Bultos, Condenados, Descarnados, Espectros, Espíritus, Fantasmas, Gentiles, Penas, Sombra, Susto. Así como otros términos empleados en relación con esas presencias: calavera, recoger los pasos e incluso entierro o tapado como elemento complementario.

2) La clase de aparecidos que pueden ser:

a) Los muertos insepultos.

b) Los desaparecidos prematuros o de manera trágica.

c) Los individuos malvados especialmente.

3) Las variadas razones de su aparición: castigo por malas acciones o comportamientos, transmisión de mensajes, recordatorio de promesas o demandas de cumplimiento, reclamo der justicia, informes acerca del Más Allá, interés en premiar a una persona (tesoro o riqueza), deseo de mantenerse en el espacio donde vivió en determinado momento y, sobre todo, solicitar sufragios (misas, rezos) para aliviar la pena que debe cumplir por suicidio o trágico final, especialmente amoroso.

4) Los lugares de aparición en el ámbito rural (caminos, bosques, pantanos, cerros, caminos, montañas, castillos), mientras que en el contexto urbano destacan cementerios, conventos, iglesias o capillas considerados cronotopos sacralizados por excelencia pero también ciertas calles, plazas, palacios, casas abandonadas o derruidas y, sobre todo, cementerios.

5) Las fechas especialmente reconocidas son la medianoche del 24 de junio o la fiesta de difuntos en noviembre.

6) Las horas preferidas por lo general se refieren a la medianoche, pero también podían presentarse en las noches de luna o la madrugada.

Los testigos o testimonios pueden ser hombres o mujeres, cuyas edades varían y con variadas reacciones, como la sensación de terror con imposibilidad de hablar hasta el pánico extremo con pérdida del sentido o incluso la muerte. Cualquier persona puede prevenirse de esas presencias insólitas, sea de forma inmediata al deceso de una persona (rituales seguidos 
en el entierro o después de él) pero también posteriormente cuando ellas se manifiestan (utilización de objetos religiosos como escapularios, rezos, misas entre otros o tradicionales (amuletos, ceremonias con participación de chamanes o curanderos).

Asimismo, debemos referirnos a los aspectos sensoriales que forman parte de los relatos escritos u orales y que enunciamos a continuación:

1) Visuales: formas corporales o tridimensionales, humanas (individuales o grupales e incluso ciertos animales, o formas evanescentes o inmateriales.

2) Auditivos: voces, ruidos y/o golpes, música.

3) Olfativos: olores desagradables en muchos casos.

4) Táctiles: contacto con huesos por lo general.

5) Reacciones corporales: escalofríos, estremecimientos, desmayos o pérdida del sentido.

\section{CONCLUSIONES}

1. La importancia del tema de la muerte y del Más Allá en las mentalidades peruanas, tal como sucede en otras sociedades, se comprueba en el conjunto de creencias, relatos y escritos que tratan de la existencia de esas presencias insólitas de la muerte.

2. La interesante relación que existe entre nuestros relatos de presencias insólitas de la muerte con los que se encuentran en otras culturas, especialmente en el occidente medieval cristiano.

3. El trabajo realizado nos ha permitido elaborar una taxonomía respecto a las apariciones, los testigos y comportamientos, los, medios de protección, así como las similitudes y diferencias en los componentes de las fuentes orales y escritas consultadas.

4. Las condiciones sociales, económicas, políticas y culturales vividas en nuestro país han desempeñado papel destacado en la elaboración de los relatos y las creencias relacionadas con los aparecidos o fantasmas.

5. La tradición oral ha sido una vía fundamental para la perennidad y adecuación de esos relatos y creencias pero igualmente debemos reconocer la importancia que han tenido las fuentes literarias, religiosas e iconográficas. 


\section{REFERENCIAS BIBLIOGRÁFICAS}

\section{GENERAL}

ALEXANDRE-BISON, D. y TREFFORT, C.

1993 A réveiller les morts. La mort au quotidien dans l'Occident médiéval. Lyon: Presses Universitaires de Lyon.

ARIÈS, P.

1975 Essais sur l'histoire de la mort en Occident du Moyen Age à nos jours. Paris: Du Seuil.

1992 El hombre ante la muerte. Madrid: Taurus.

DELUMEAU, J.

1978 La peur en Occident (XIV-XVIIe siècles): une cité assiégée. Paris: Fayard.

SAN AGUSTÍN

1995 La piedad con los difuntos. En Escritos varios (2), Madrid: BAC.

VOVELLE, M.

1974 Mourir autrefois, Attitudes collectives devant la mort aux XVIIe et XVIIIe siècles. Gallimard/Julliard.

2003 La mort en Occident de 1300 à nos jours. Paris: Éditions Gallimard.

2005 L'heure du grand passage. Chronique de la mort. Paris: Gallimard.

\section{ESPECÍFICA}

CABAL, C.

1993 Mitología ibérica. Supersticiones, cuentos y leyendas de la vieja España. Oviedo: Grupo editorial asturiano.

\section{LE GOFF, J.}

1989 El nacimiento del purgatorio. Madrid: Taurus.

\section{LECOUTEUX, C.}

1999a Chasses fantastiques et cohortes de la nuit au Moyen Age. Paris.

1999b Demonios y genios comarcarles en la Edad Media. Palma de Mallorca: José de Olañeta Editor.

1999c Fantasmas y aparecidos en la Edad Media. Palma de Mallorca: José de Olañeta Editor. 
LISÓN TOLOSANA, C.

2004 La Santa Compaña: Fantasías reales, realidades fantásticas. Madrid: Akal Ediciones.

SCHMITT, J.C.

1992 Historia de las supersticiones. Barcelona: Crítica.

1994 Les revenants. Les vivants et les morts dans la société médiévale. Paris: Éditions Gallimard.

FUENTES EDITADAS.

BÉCQUER, G. A.

1970 Leyendas en Obras Completas, Madrid: Aguilar.

BERTI, E. (comp.)

2009 Fantasmas, Buenos Aires: Adriana Hidalgo.

CORZO, I.

2013 Lugares encantados y misterios de Lima, Lima: Contracultura.

IRVING, W.

1959 Leyendas del Alhambra y de la conquista árabe de España. Barcelona: Iberia.

FLORES, G.

2010 Almas, fantasmas y tunchis. Lima: Editorial San Marcos.

JOYNES, A.

2001 Medieval Ghosts Stories, Suffolk: Boydell Press.

NICOLI SEGURA, P.

2005 Arequipa: fantasmas y leyendas, Arequipa: Editorial Distribuidora Alexis.

2005 Arequipa y sus misterios, Arequipa: Editorial Distribuidora Alexis. 2006 Arequipa y sus enigmas, Arequipa: Editorial Distribuidora Alexis.

2008 Mitos y leyendas de Arequipa, Arequipa: Editorial Distribuidora Alexis.

PALMA, R.

1957 Tradiciones peruanas completas, Madrid, Aguilar, 1957. 
RÉJU, D.

1973 Les demeures de l'impossible. Fantômes et maisons hantées, Paris: Belfond.

VV.AA.

1972 Las mejores historias insólitas, Barcelona: Bruguera.

ANEXO I

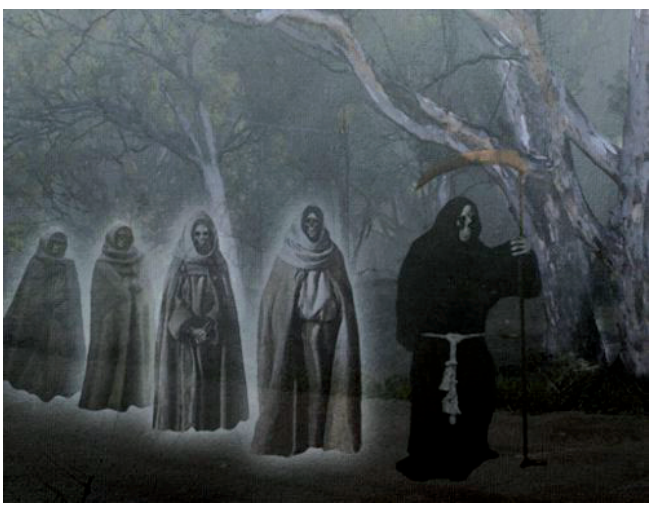

Figura 1: Representación de la Santa Compaña o Procesión de las ánimas

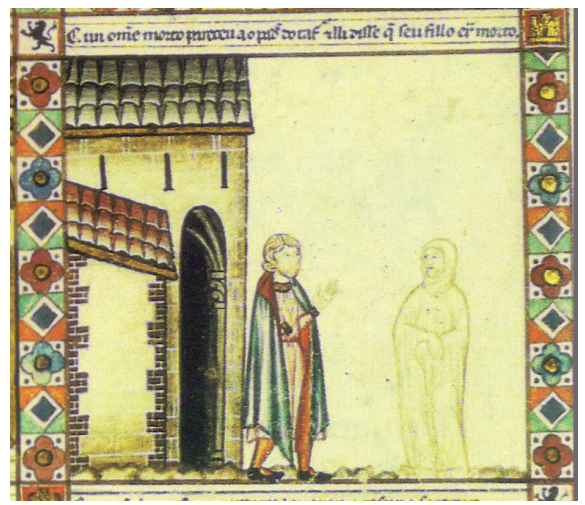

Figura 2: Representación fantasmal en Las cantigas de Santa María 


\begin{abstract}
ANEXO II
En F. ZORA CARVAJAL, (1969) Tacna, historia y folklore.

Tacna: Editorial Santa María, pp. 197-200.
\end{abstract}

\title{
UN EXTRAÑO IDILIO
}

- Volveré dentro de un año.

- Confío en ti.

- Adiós, Fresia. Te escribiré.

- Adiós, Efraín.

Así fue la despedida, junto a la escalinata del muelle de Arica, en una mañana del año 1910.

Efraín viajó a una ciudad lejana del sur. Razones poderosas de su profesión y de orden familiar lo obligaban a ello. En el dedo anular de su mano izquierda llevaba el simbólico aro de compromiso matrimonial.

$* * *$

Pasan los días, las semanas y los meses. Cartas florecidas de romance se cruzan con regularidad entre Fresia y Efraín.

Cumplido el año, Efraín no pudo volver. Pero escribió manteniendo su compromiso.

Pasan otros días y otros meses.

De pronto, cesa el intercambio epistolar.

Fresia empalidece día a día. Adolece de una extraña enfermedad.

$* * *$

Año 1917. Efraín ha retornado. No había anunciado su viaje. Viene a cumplir su compromiso, aunque tardíamente. Portaba comunicaciones y obsequios de sus familiares para Fresia y para la madre de ésta, doña Susana. Además, está satisfecho del ascenso que ha obtenido en la poderosa empresa comercial, de la cual es alto y antiguo empleado.

Efraín se aloja en un hotel, a su desembarco en las primeras horas de la noche.

Al día siguiente visitará a su novia. Quiere darle una sorpresa agradable.

$* * *$

Después de la comida en el hotel, Efraín y un amigo, compañero de viaje, deciden hacer un recorrido por la ciudad. Han pasado siete años. Las calles están iluminadas y alegres. Era noche de fiesta.

A las diez de la noche llegan hasta la puerta del Club X. Música, algazara. Se trata de un baile social. Hay numerosa concurrencia. 
Los recién llegados cambian ideas.

- Entremos.

- Sí.

Y, provistos de sus tickets, Efraín y su amigo avanzan hacia los salones, donde ya ha empezado el baile.

$* * *$

Efraín se detiene sorprendido. ¿Será una visión? ¿Se trata, tal vez, de un parecido de persona? Le da un vuelco el corazón.

Allí está Fresia. Vestida de blanco. Bella. Sonriente. Alegre.

Y, cuando se aproxima Efraín, ella se vuelve, y, con sonrisa de tristeza, le dice:

- Te he esperado tanto tiempo, Efraín.

- Muchos inconvenientes han retardado mi regreso. Perdóname.

- Fuiste ingrato conmigo.

- He venido a cumplir mi promesa.

Sigue el diálogo de reproches, amable y triste.

La orquesta desgrana las notas de un vals de Strauss.

Efraín y Fresia bailan animadamente.

El mundo ha cambiado, en verdad. ¡Cuántos sucesos han ocurrido en siete años! Pero, el reencuentro es feliz. El idilio se reanuda como dos serpentinas que se atan en noche de fiesta.

$* * *$

- Efraín, ya debo irme a casa. Mamá me ha dado permiso sólo hasta las doce de la noche. Mira, Faltan pocos minutos.

- Te acompañaré.

- Vamos.

A la salida del Club, Fresia siente frío. Efraín se despoja de su grueso gabán, y con él abriga a Fresia. Y, avanzan calle arriba.

Ya están frente de la casa de Fresia. Dan las doce.

Se abre la puerta.

- Mañana vendré a saludar a tu mamá y a verte.

- Te esperaré, Efraín... ¿Y tu abrigo?

- Quédate con él. Mañana lo recogeré.

- Hasta mañana.

- Hasta mañana. Adiós. 


\section{$* * *$}

Al día siguiente, Efraín acude, puntualmente, a la cita.

Llama a la puerta.

Le recibe la señora Susana, quien viste traje oscuro. Ingresan al salón.

- Anoche vi a Fresia, y la acompañé hasta la puerta. Era hora avanzada y no quise importunarla a usted ...

La señora Susana se queda mirándole son asombro.

- He tardado, en verdad, mucho -continúa Efraín-. Muchos inconvenientes han impedido mi regreso. Pero, vengo a cumplir mi compromiso. Usted perdonará ... desde luego ...

La señora prorrumpe en llanto.

- Pero, señora... ¿Qué ocurre?

- Pero ... ya usted ... no puede casarse con Fresia ...

- ¡Cómo!... He sido ingrato, verdad... Pero ella me ha perdonado... y usted... también... debe perdonarme...

- Es que...

- No comprendo...

- Fresia ya no existe... Murió hace dos años... Fue una gran desgracia... No tuve valor para escribirle a usted dándole la noticia...

- Usted bromea, señora... Si anoche hablé con ella... La vi... ¡Es horrible!

$* * *$

En la tarde de aquel día, doña Susana y Efraín se encaminaron al cementerio, portando ramos de rosas blancas.

Llegan hasta el mausoleo de mármol blanco, que fulge a los rayos del sol de la tarde.

La inscripción está allí. Nítida, precisa, dolorosa:

Fresia N.

Falleció el 5 de agosto de 1915.

Y, luego, contemplan, con miradas de espanto, de sorpresa indefinible, la cruz que orna la tumba.

Allí, junto a la cruz, está el grueso gabán de tonos oscuros, el mismo gabán que Efraín había colocado sobre los hombros de Fresia, en la noche anterior, al salir de la fiesta. 